\title{
Influencing factors of Mental Health of Adolescents at School Level
}

\author{
Dr. P. Lavanya Kumari \\ UGC Post Doctoral Fellow, Department of Population Studies, Sri Venkateswara University, Tirupati, \\ Andhra Pradesh, INDIA,
}

\begin{abstract}
Mental health(MH) is a state of emotional and psychological well-being in which an individual is able to use his or her cognitive and emotional capabilities, function in society, and meet the ordinary demands of everyday life. Their behaviour has impact on National Health Indicators like maternal and infant mortality.Adolescents are vulnerable to STIs, HIV/AIDS and Sexual-Abuse when there is negative impact of parents, teachers and their peer group especially upon their mental health. Several studies have emphasised serious concerns relating to adolescents that need urgent attention towards their mental health at school level itself. Caring, supportive environment will promote optimum development of Physical, Emotional and Mental health among Adolescents. Hence, the factors 'Parent Child Relation (PCR)' 'School Environment (SE)' and 'Peer Relation (PR)' are considered and their influence on mental health of adolescents is studied in this paper. Results disclose that there is high significant influence of good peer relation and healthy school environment on mental health of adolescents whereas 'Parent Child relation' has influenced moderately. It has been observed that the contribution of 'Parent Child Relation', 'Peer Relation' and 'School Environment' towards 'Mental Health' is more in girls than boys. Adolescents of Private Schools have strong parent child relation when compared to the adolescents of Government schools. But age and class of the adolescents have not shown any influence on their Mental Health due to PCR, SE and PR as there is no much gap among them.
\end{abstract}

Keywords: Mental Health (MH), Parent Child Relation(PCR), Peer Relation(PR) and School Environment(SE)

\section{Introduction}

Mental Health is a state of emotional and psychological well-being in which an individual is able to use his or her cognitive and emotional capabilities, function in society, and meet the ordinary demands of everyday life. According to Schreiber (1951), mental health means the ability of an individual to pursue reasonable, purposeful goals; use his capacities and talents fruitfully. As part of one's overall health, mental and emotional health or wellbeing is a necessary condition to enableone to manage one's life successfully. It gives him or her capacity to live life in fulfillment of what he or she wants to achieve in accordance to the available resources. This condition also provides an individual the capacity to be resilient to the stresses he meets and to respond to these challenges without having to compromise his well-being. This also makes him productive and fruitful for himself and his community.

Mental health is important as it affects everything one does - how one sleeps, what one eats, the risk one will take and the types of things one does to relax and enjoy one self. Some of the criteria for good mental health are

Adequate feeling of security

$>$ Adequate self-evaluation

$>$ Adequate spontaneity and emotionality

$>$ Efficient contact with reality

Adequate bodily desires and the ability to gratify them

$>$ Adequate self-knowledge

$>$ Integration and consistency of personality

$>$ Adequate life goals

$>$ Ability to learn from experience

$>$ Ability to satisfy the requirements of the group

$>$ Adequate emancipation from the group or culture

According to National Center for Education in Maternal and Child Health, 'every child and adolescent deserves to experience joy, have high self-esteem, have friends, acquire a sense of efficacy, and believe that he or she can succeed in life'. 
World Mental Health Day - October 10, 2008

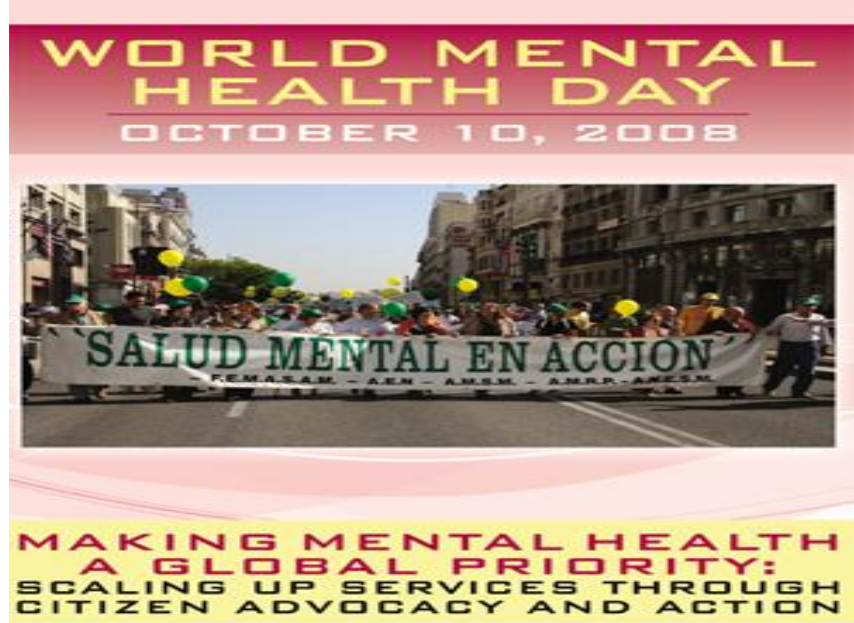

"Mental health is of paramount importance for personal well-being, family relations and an individual's ability to contribute to society," Mr. Ban said in his message on World Mental Health Day, observed annually on 10 October.

\subsection{Need for the study}

The National Institute of Mental Health (NIMH) has identified emotional and behavioral problems as serious barriers for teaching and learning. NIMH reports that between 5-9 percent or 2.5-5.0 million children are not learning and achieving in school because of these barriers. So the mental health and psychological services is a high priority need for developing healthy children.

Hence this paper aims at to study the contribution of 'Parent Child Relation(PCR)', 'Peer Relation $(P R)$ ' and 'School Environment(SE)' on the 'Mental Health(MH)' of adolescents particularly school going children.

\subsection{Parent-Child Relation(PCR)}

Parent-child connectedness can be defined as the degree of closeness experienced in the relation that children have with their parents. According to research, how children experience the connection with their parents seems to be more important than how the parent reports or perceives the level of connection. The parent-child relation consists of a combination of behaviors, feelings, and expectations that are unique to a particular parent and a particular child. The relation involves the full extent of a child's development.

In recent years, more and more research has been published showing the importance of parent-child connectedness as a protective factor related to several youth health outcomes including pregnancy, HIV/STD, drug abuse, tobacco use, and delinquency. In fact, at a recent World Health Organization (WHO) meeting in Geneva, family connectedness was identified as one of the top five protective factors related to youth wellbeing.

\subsection{Peer Relation(PR)}

Peers are people of about the same age who share similar interests or activities. Friends are special peers with whom we form close personal relations. The quality of adolescents' friendships is also important because of the numerous influences that having supportive, meaningful peer relations has impact on adolescent adjustment. The importance of peers during early adolescence coincides with changes in individuals' needs for intimacy. As children begin to share secrets with their friends, loyalty and commitment develop. During adolescence, the search for intimacy intensifies, and self-disclosure between best friends becomes an important pastime. Teenagers, especially girls, spend a good deal of time discussing their innermost thoughts and feelings, trying to understand one another. The discovery that they tend to think and feel the same as someone else becomes another important basis of friendship. It is true that adolescents from more troubled households tend to be more influenced by peers than parents. And, in situations where parents are unable to relax their authority, teenagers are more likely to become peer oriented. However, in most cases, peer influence compliments the influence of parents.

\subsection{School Environment}

The school is the most significant social context in the life of a child as almost one third of a day is spent here. The school is not only an organization to teach cognitive skills and to impart information; it is also a 
social system in which the child learns the rules of morality, social conventions, attitudes and modes of relating to each other. Thus, for an adolescent, the school life signifies both adjustment and achievement, entailing the emotional as well as the cognitive aspects of life.

As school is the second most intimate environment next to the home it has fascinating influence on the child's academic performance, it acts as an agency equipped with multiple opportunities that stimulates the child to explore, investigate and experiment in many ways.

School takes the child on well guided tour into areas beyond the home circle. School experiences play an important value formation. Many values learnt at home will be reinforced, some will be challenged or shaken, other will perhaps be discarded. The school serves as a testing ground on which the child develops and strengthens his sense of identity.

\section{Review}

\subsection{Studies on impact of Parent Child Relation on Mental Health of Adolescents}

The importance of good parent-child relation in the healthy development of individuals in later life has been well documented in literature. Parents play a key-role in providing a sound mental health for their children.According to Suman et.al $(2003)^{31}$ the achievement is higher in children who perceive their parents as loving and demanding. Steinberg et.al $(1992)^{28}$ reported that adolescents who described their parents as authoritative-warm, firm and democratic had better school performance and stronger school engagement. In addition, parental authoritativeness was associated with higher levels of school involvement and more encouragement of academic success. Uma Devi et.al (2004) $)^{33}$ is bringing forth efforts to strengthen family environments to have emotionally intelligent citizens of tomorrow. Prahbhjot Molhi $(2000)^{21}$ in his article describes effective discipline requires that parents in the context of a positive, supporting relation use disciplining strategies that help to increase desired behaviour and at the same time reduce or eliminate inappropriate behaviour.

Sudhakotyal et.al's $(1998)^{29}$ findings revealed that parental expectations have given rise to academic stress and strain in the youths of today. Socio-personal factors like joint family, non-working mothers and fathers in business, low parented education and family income also act as adverse stresses. Shanty, K.J et.al $(1998)^{26}$ makes it clear that intensity of discipline significantly influence the direction and type of aggressive reaction to frustrating situations. Suman L.N et.al $(1997)^{30}$ proved that the achievement motivation was higher when adolescents perceived their parents as loving and demanding. Kamaljeet Kaur Mehta $(1994)^{17}$ explored the parent child Relation (PCR) on children and found that the PCR to be a significant predictor of intelligence in preschool children.Sowaid, M et.al $(1987)^{27}$ found that restrictive attitude of father and protecting attitudes of both father and mother is inversely related to achievement and motivation of Paharia students. Loving attitude of father is positively related to achievement and motivation. Sociologists and psychologists have suggested that parental involvement with child is a pivotal process through which parents influence academic competence (Brody, Stoneman \& Flor 1995) ${ }^{2}$.

\subsection{Studies on impact of Peer Relation on Mental Health of Adolescents}

Colarossi and Eccles $(2003)^{7}$ have found that support from friends is related to lower depression and higher self-esteem in adolescents. Studies have shown that support from an adolescents' peer group has consistently been associated with adjustment, specifically lower depression and hyperactivity, higher leadership, and better social skills (Rueger et al. 2010) ) $^{24}$. Contradictory evidence comes from other studies that have shown positive correlations between peer support and negative outcomes such as externalizing problem behaviors (Rueger et al. 2010) ${ }^{24}$. In one study, researchers Scholte, Van Lieshout, and Van Aken (2001) ${ }^{25}$ found that adolescents who reported that they did not have a best friend experienced lower levels of social support and tended to report feeling lonely and isolated from peers. Because of the increasing importance and impact of supportive peer relations for both positive and negative outcomes, it is important to consider the factors that influence adolescents' ability to form supportive friendships.

Integration into a peergroup is likely to help adolescents develop a high level of school coherence and confidence in their ability to influence their presenting situations and to achieve desired academic performance (Hepler, 1994; Keefe \&Bemdt, 1996; Kemple, 1991; Wentzel, 1991) ${ }^{14}$. Research has publicized that children who are accepted by their peers are more inclined to follow rules and stay out of trouble (Wentzel\& Asher, $1995)^{35}$, which is likely associated with higher academic performance. A variable that captures such behavior, avoidance of problem behavior, is entered into the analysis as a third potential bridge between peer group acceptance and academic performance.

Available research suggests that peer group acceptance may be associated with poorer academic performance among adolescents from lower socio-economic homes (Cauce, Felner, \& Primavera, 1982; Luther, $1995)^{4}$. The level of social toxicity (Garbarino, 1995) ${ }^{13}$ in many lower socio-economic neighborhoods creates a poor environment for individual development and the formation of peer relations that encourage academic 
success (DuRent, Getts, Cadenhead, Emans, \& Woods, 1995) ${ }^{11}$. Low-income parents may have less time and fewer resources than higher socio-economic parents to supervise their children and to provide them with structured recreational and social activities (Garbarino, 1992) ${ }^{12}$. In these situations, peers may play a more active and determining role in influencing theacademic performance of adolescents. According to Collins, $(2003)^{8}$; Connolly \& Goldberg, $(1999)^{9}$, peer relations may have mental health benefits, including the provision of social support, enhancement of self-esteem, preparation for adult relations, and the development of intimacy.

The peer group is important for adolescent social and emotional development because youngsters derive a sense of belonging and acceptance from peers (La Greca \& Prinstein, 1999) ${ }^{20}$. Longitudinal studies also have linked childhood peer rejection to symptoms of internalized distress in adolescence, suggesting a causal role for peer rejection (Coie, Lochman, Terry, \& Hyman, 1992) ${ }^{6}$ and Kupersmidt \& Patterson, 1991) ${ }^{19}$. Prospective studies also indicate that symptoms of depression predict subsequent peer rejection. Vernberg $(1990)^{34}$ followed early adolescents over a school year, finding that depressive symptoms early in the year, predicted higher levels of peer rejection 6 months later. Similarly, Little and Garber $(1995)^{21}$ found that symptoms of depression among early adolescents predicted an increase in peer rejection over a 3-month period

\subsection{Studies on impact of School enviroment on Mental Health of Adolescents}

Ramanath Kundu and Jayanti Basu $(1991)^{18}$ indicated that academic achievement and neu roticism were related to each other and could be predicted from various modes of frustration reactions. Devi.S and K.Mayuri $(2003)^{10}$ concluded that school factors like well qualified teachers, good curriculum and subject matter on time, impressive method of teaching and teacher-student interaction have contributed significantly with the academic achievement. Study of Suneetha, B. et.al $(2001)^{32}$ reveals that out of 9 factors observed, majority of them exhibited significant positive correlation with academic achievement. So it was concluded that school, the second most intimate environment next to home has fascinating effect on the child's high performance at school. Cairns and Lloyd $(2005)^{3}$ extracted that the school work and exams was the most cited cause of stress for young people of 16 years old. Anonymous (2004) ${ }^{1}$ has examined trends between 1983 and 2003 in young people's emotional health and wellbeing, as reported through their young people and health survey and has found that young people are increasingly more likely to worry quite a lot about school and career problems.

\section{Methodology}

This section deals with the methodology adopted for the study. It includes the research approach, design for the study, the setting, sample and sampling technique, development of the tools, pilot study, data collection procedure and data analysis.

\subsection{Research approach}

Survey method has been adopted to study the primary aim of the researcher i.e to observe the influence of Parent-Child Relation (PCR), School Environment(SE) and Peer Relation(PR) on Mental Health(MH) of adolescents at high school level and also to find the impact of demographic variables such as school, class and sex on mental health of adolescents.

\subsection{Population}

The population for the present study consists of both boys and girls studying $8^{\text {th }}$ to $10^{\text {th }}$ classes from Government and Private schools in Chittoor district of Andhra Pradesh.

\subsection{Sample and Sampling Technique}

The survey was conducted at Government and Private high schools located at Chittoor district. Five Government Schools and Five Private Schools are selected at random and from each school 30 students in which 15 boys and 15 girls are selected. Further such a care has been taken by researcher that 5 boys and 5 girls must include from each of 8 th, $9^{\text {th }}$ and $10^{\text {th }}$ classes so that the total students from Government and Private schools are 150 each. The sample distribution according to class and sex is exhibited in the following table.

Sex and class distribution of the adolescents for the study

\begin{tabular}{|c|c|c|c|c|c|c|c|}
\hline \multirow{2}{*}{ School } & \multicolumn{2}{|c|}{$8^{\text {th }}$ class } & \multicolumn{2}{c|}{$9^{\text {th }}$ class } & \multicolumn{2}{c|}{$10^{\text {th }}$ class } & \multirow{2}{*}{ Total } \\
\cline { 2 - 7 } & Boys & Girls & Boys & Girls & Boys & Girls & \\
\hline Government & 25 & 25 & 25 & 25 & 25 & 25 & 150 \\
\hline Private & 25 & 25 & 25 & 25 & 25 & 25 & 150 \\
\hline \multirow{2}{*}{ Total } & 50 & 50 & 50 & 50 & 50 & 50 & \multirow{2}{*}{300} \\
\cline { 2 - 7 } & \multicolumn{2}{|c|}{100} & \multicolumn{2}{|c|}{100} & \multicolumn{2}{|c|}{100} & \\
\hline
\end{tabular}




\subsection{Demographic variables}

1. School: It is high school run by Government or Private management.

2. Sex: Adolescent boy or girl who were included for the study.

\subsection{Study variables}

1. Mental Health(MH): It refers to the adolescent's Mental Health. To measure the mental health of adolescents one hundred questions are selected from the mental health analysis (MHA) consisting of 200 "Yes" or "No" type questions, developed by Clark,W.W, Tiegs, E.W. and Thrope, L.P.Manual (1959) and its Reliability and Validity is checked again.

2. Parent-Child Relation(PCR): It refers to the child's interpretation of his/her interaction with parents. A standardized tool is adapted from Rao N $(1989)^{23}$ to quantify the relation.

3. School Environment(SE): It refers to the adolescent's perception of social, emotional and physical climate of the educational institution in which he/she is studying. A tool is considered from Joyce.L.Epstein \& Jame M.Mcpartland (1976) ${ }^{16}$ to assess the School Environment.

4. Peer Relation(PR): It refers to the adolescent's perceived psychosocial behaviour of his/her friend. Peer relation scale was taken from James R. Ciesla and Ping Yao(2011) ${ }^{15}$ in order to measure the relation between adolescents and their friends.

\subsection{Statistical Analysis}

Collected data is properly coded and systematically analysed using appropriate statistical techniques viz., frequencies, percentages, cross tabulations, chi-square test, independent sample t-tests, Simple and Multiple linear regressions with the help of SPSS.20. Results are summarised as per the levels of significance.

\section{Results And Discussion \\ 4.1 Impact of School on Mental Health, Parent Child Relation, Peer Relation and School Environment}

Table-1: Mental Health by School

\begin{tabular}{|c|c|c|c|c|c|}
\hline \multicolumn{2}{|c|}{} & \multicolumn{3}{|c|}{ Level of Mental Health } & \multirow{2}{*}{ Total } \\
\cline { 3 - 5 } \multicolumn{2}{|c|}{} & Poor & Average & Good & \\
\hline \multirow{3}{*}{ SCHOOL } & \multirow{2}{*}{ Govt. School } & 44 & 67 & 39 & 150 \\
\cline { 3 - 6 } & & $29.3 \%$ & $44.7 \%$ & $26.0 \%$ & $100.0 \%$ \\
\cline { 2 - 6 } & \multirow{2}{*}{ Private School } & 37 & 72 & 41 & 150 \\
\cline { 3 - 6 } & $24.7 \%$ & $48.0 \%$ & $27.3 \%$ & $100.0 \%$ \\
\hline \multicolumn{2}{|c|}{ Total } & 81 & 139 & 80 & 300 \\
\cline { 3 - 6 } & $27.0 \%$ & $46.3 \%$ & $26.7 \%$ & $100.0 \%$ \\
\hline
\end{tabular}

Table-1 reveals that, $27 \%$ of adolescents from both Government and Private Schools have poor status of mental health and the remaining adolescents (73\%) are with moderately better status of Mental Health. It is also evident $(p>0.05)$ that type of school has no definite association with mental health of adolescents.

Table-2: Parent Child Relation by School

\begin{tabular}{|c|c|c|c|c|c|}
\hline \multicolumn{2}{|c|}{} & \multicolumn{3}{|c|}{ Level of Parent Child } & \multirow{2}{*}{ Relation } \\
\cline { 3 - 5 } \multicolumn{2}{|c|}{} & Low & Moderate & High & \\
\hline \multirow{4}{*}{ SCHOOL } & Govt. & 55 & 63 & 32 & 150 \\
\cline { 3 - 6 } & School & $36.7 \%$ & $42.0 \%$ & $21.3 \%$ & $100.0 \%$ \\
\cline { 2 - 6 } & Private & 20 & 87 & 43 & 150 \\
\cline { 3 - 6 } & School & $13.3 \%$ & $58.0 \%$ & $28.7 \%$ & $100.0 \%$ \\
\hline \multicolumn{2}{|c|}{ Total } & 75 & 150 & 75 & 300 \\
\cline { 3 - 6 } & $25.0 \%$ & $50.0 \%$ & $25.0 \%$ & $100.0 \%$ \\
\hline
\end{tabular}

From table-2, the Chi-square test $(\mathrm{p}<0.01)$ suggests the significant association between type of school and level of parent child Relation at $1 \%$ level. So, it is clear that the more adolescents from private school seem to have a better relation with their parents than that of adolescents from Government schools. Because the parent's good financial status and pampering their children might have contributed the children from private school to express satisfactory relation towards their parents. 


\begin{tabular}{|c|c|c|c|c|c|}
\hline & & \multicolumn{3}{|c|}{ Level of Peer Relationship } & \multirow{2}{*}{ Total } \\
\hline & & Low & Moderate & High & \\
\hline \multirow{4}{*}{ SCHOOL } & \multirow{2}{*}{ Govt. School } & 43 & 68 & 39 & 150 \\
\hline & & $28.7 \%$ & $45.3 \%$ & $26.0 \%$ & $100.0 \%$ \\
\hline & \multirow{2}{*}{ Private School } & 37 & 67 & 46 & 150 \\
\hline & & $24.7 \%$ & $44.7 \%$ & $30.7 \%$ & $100.0 \%$ \\
\hline \multirow{2}{*}{\multicolumn{2}{|c|}{ Total }} & 80 & 135 & 85 & 300 \\
\hline & & $26.7 \%$ & $45.0 \%$ & $28.3 \%$ & $100.0 \%$ \\
\hline
\end{tabular}

The Chi- square test ( $p>0.05)$ from table- 3 is supporting that, the type of school in which the children are studying, has not influenced the relation with their friends. Irrespective of school where they study, adolescents have the same level of peer relationship.

Table-4: School Environment by School

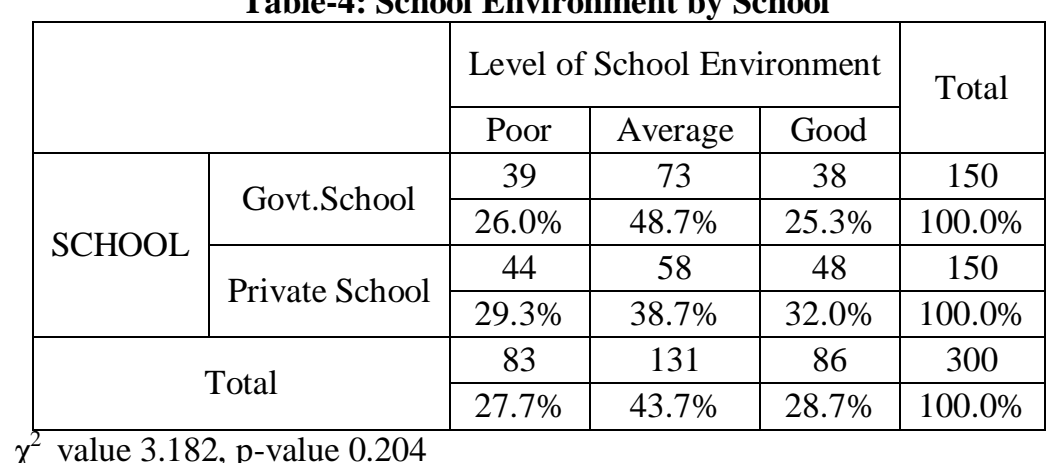

Table-4 indicates that the type of school has no association with Level of School Environment. It is also interesting to note that adolescents from Private school have high (32\%) school environment inventory than that of Government school (25\%). Statistically, there is no association between type of school and its environment which means that irrespective of physical facilities, the social and emotional environment between the teacher and students might have led the adolescents to express the same opinion towards their school.

Hence it can be concluded that the type of school has influence only on Level of Parent Child Relation, in which private school children have good relation than the children from Government schools, but not on Mental Health, Peer Relation and School Environment. The same conclusion can be observed from the summary of independent sample t-test showed in table- 5 with respect to average scores also.

Table-5: Independent sample t-test by School

\begin{tabular}{|c|c|c|c|c|c|c|}
\hline Variable & School & $\mathbf{N}$ & Mean & Std. Deviation & t-value & p-value \\
\hline \multirow{2}{*}{ Mental Health } & Govt. & 150 & 73.56 & 9.405 & 1.177 & 0.240 \\
\cline { 2 - 8 } & Private & 150 & 74.72 & 7.560 & & \\
\hline \multirow{2}{*}{ Parent Child Relation } & Govt. & 150 & 116.41 & 24.065 & $4.590^{* *}$ & 0.000 \\
\cline { 2 - 8 } & Private & 150 & 127.47 & 17.080 & & \\
\hline \multirow{2}{*}{ Peer Relation } & Govt. & 150 & 35.98 & 5.965 & 1.493 & 0.136 \\
\cline { 2 - 8 } & Private & 150 & 36.94 & 5.139 & & \\
\hline \multirow{2}{*}{ School environment } & Govt. & 150 & 42.57 & 8.672 & 1.219 & 0.224 \\
\cline { 2 - 8 } & Private & 150 & 43.75 & 7.988 & & \\
\hline
\end{tabular}


4.2 Impact of Sex on Mental Health, Parent Child Relation, Peer Relation and School Environment

\begin{tabular}{|c|c|c|c|c|c|c|}
\hline \multicolumn{7}{|c|}{ Table-6: Independent sample t-test by gender } \\
\hline Variable & Gender & $\mathrm{N}$ & Mean & Std. Deviation & t-value & p-value \\
\hline \multirow{3}{*}{ Mental Health } & Boys & 150 & 73.53 & 7.860 & 1.245 & 0.214 \\
\cline { 2 - 8 } & Girls & 150 & 74.75 & 9.151 & & \\
\hline \multirow{3}{*}{ Parent Child Relation } & Boys & 150 & 120.91 & 22.112 & 0.827 & 0.409 \\
\cline { 2 - 8 } & Girls & 150 & 122.97 & 21.009 & & \\
\hline \multirow{2}{*}{ Peer Relation } & Boys & 150 & 36.13 & 5.161 & 1.035 & 0.301 \\
\cline { 2 - 8 } & Girls & 150 & 36.79 & 5.966 & & \\
\hline \multirow{2}{*}{ School Environment } & Boys & 150 & 43.02 & 8.253 & 0.290 & 0.772 \\
\cline { 2 - 8 } & Girls & 150 & 43.30 & 8.459 & & \\
\hline
\end{tabular}

Table-6 reveals that there is no significant difference between Boys and Girls with respect to Mental Health, Parent Child Relation, Peer Relation and School Environment since p-values are greater than 0.05 . From this observation author wanted to examine whether influence of PCR, PR and SE on MH in boys and girls is at same level or not. Further three Simple Linear Regression models had been built for boys and girls separately. Results are exhibited in table-7.

\subsection{Contribution of Parent Child Relation, Peer Relation and School Environment on Mental Health by Sex (Regression Analysis)}

Table-7: Regression models on Mental Health of Adolescents

\begin{tabular}{|c|c|c|c|}
\hline Model & Predictors & Male & Female \\
\hline 1 & $\begin{array}{l}\text { Parent Child Relation } \\
\text { Score (PCR) }\end{array}$ & $\begin{array}{c}\mathrm{MH}=44.036^{* *}+0.242(\mathrm{PCR}) * * \\
\left(\mathrm{R}^{2}=0.462\right)\end{array}$ & $\begin{array}{c}\mathrm{MH}=32.518^{* *}+0.343(\mathrm{PCR})^{* *} \\
\left(\mathrm{R}^{2}=0.622\right)\end{array}$ \\
\hline 2 & Peer Relation Score (PR) & $\begin{array}{c}\mathrm{MH}=24.643 * *+1.353(\mathrm{PRS}) * * \\
\left(\mathrm{R}^{2}=0.789\right)\end{array}$ & $\begin{array}{c}\mathrm{MH}=22.794 * *+1.412(\mathrm{PRS}) * * \\
\left(\mathrm{R}^{2}=0.848\right)\end{array}$ \\
\hline 3 & School Environment (SE) & $\begin{array}{c}\mathrm{MH}=45.269^{* *}+0.657(\mathrm{SE}) * * \\
\left(\mathrm{R}^{2}=0.476\right)\end{array}$ & $\begin{array}{c}\mathrm{MH}=40.345^{* *}+0.795(\mathrm{SE})^{* *} \\
\left(\mathrm{R}^{2}=0.540\right)\end{array}$ \\
\hline 4 & PCR, PR and SE & \multicolumn{2}{|c|}{$\begin{array}{c}\mathrm{MH}=19.687 * *+0.088(\mathrm{PCR})^{* *}+1.001(\mathrm{PR})^{* *}+0.168(\mathrm{SE})^{* *} \\
\left(\mathrm{R}^{2}=0.873\right)\end{array}$} \\
\hline
\end{tabular}

Dependent Variable: Mental Health (MH)

From the table-7, it can be observed that only $46 \%$ of Mental Health of boys is explained by the Parent Child Relation where as this is $62 \%$ in girls. In second model, Peer Relation explains $46 \%$ and $62 \%$ of Mental Health of boys and girls respectively. Similarly by the third model it can be identified that $48 \%$ and $54 \%$ of Mental Health is explained by School Environment in boys and girls respectively. In all the models Mental Health of girls is highly influenced by Parent Child Relation, Peer Relation and School Environment when compared to that of boys. It can be viewed in figure-1. 


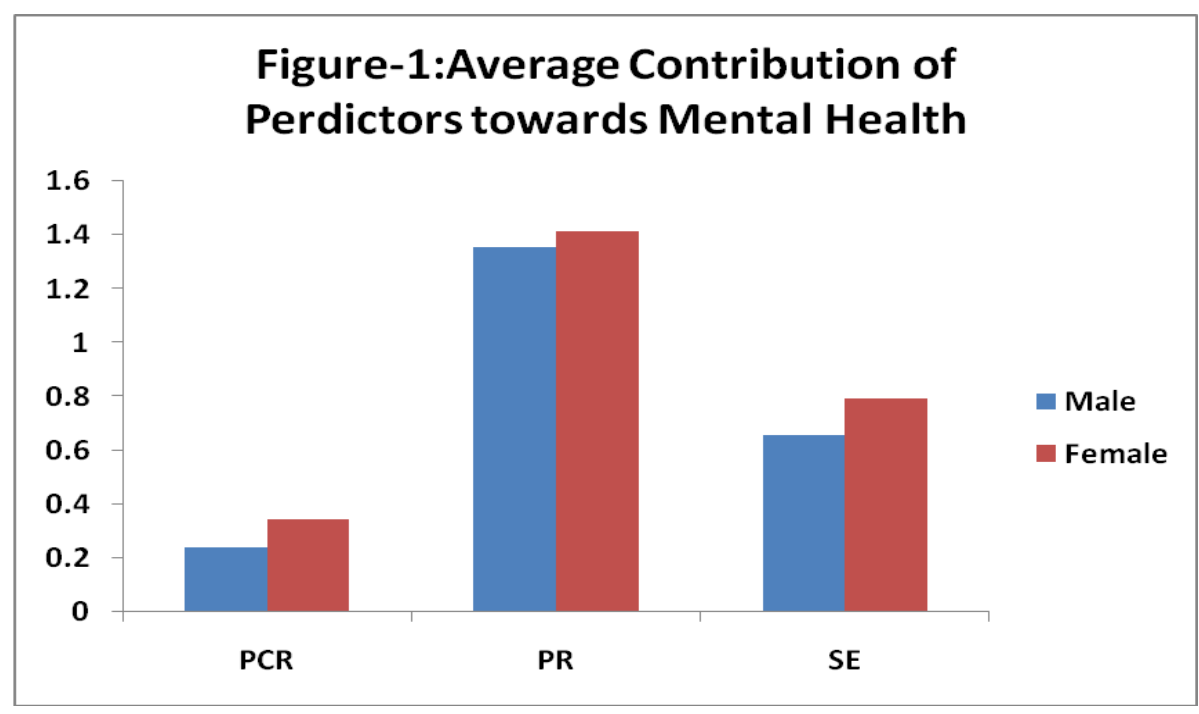

Finally a Multiple Linear Regression model enlightens that Mental Health of adolescents at school is highly influenced by Peer Relation then by School Environment and then by Parent Child Relation.

Hence it can be inferred that a good Parent Child Relation, Peer Relation and School Environment enhances the Mental Health of girls more than boys.

\section{Acknowledgements}

Author is very grateful to the authors who developed tools for various measures used in this study and also to Head Masters of the opted high schools in Chittoor district, Andhra Pradesh for providing necessary information.

\section{Conclusion}

In this paper three influencing factors of Mental Health are studied and found that irrespective of gender, adolescents have the same level of Parent Child Relation (PCR), Peer Relation (PR), School Environment (SE) and Mental Health (MH). But adolescents of Private Schools have strong significant parent child relation when compared to the adolescents of Government schools. Interestingly girls have been highly and positively influenced by the relation with parents, relation with friends and also by good school environment with respect to their Mental Health than that of boys. Moreover, Peer Relation and School Environment are highly influencing the adolescent's Mental Health than by their relation with parents.

\section{References}

[1] Anonymous, 2004, Trends: young people and emotional health and well being. School Health Edu. Unit, England, pp. 25-28.

[2] Brody, G. H., Stoneman, Z., \& Flor, D. (1995). Linking family processes and academic competence among rural African American youths. Journal of Marriage and the Family, 57, 567-579.

[3] Cairns E., and Lloyd, K. (2005), Stress at Sixteen (Research Update), Belfast: Northern Ireland Social and Political Archive (ARK).

[4] Cauce, A. M., Felner, R. D., \& Primavera, J. (1982). Social support in high-risk adolescents: Structural components and adaptive impact. American Journal of Community Psychology, 10, 417- 428.

[5] Clark,W.W, Tiegs, E.W. and Thrope, L.P.Manual (1959), Mental Health Analysis, California Test Bureau.

[6] Coie, J.D., Lochman, J.E., Terry, R. \& Hyman, C. (1992). Predicting early adolescent disorder from childhood aggression and peer rejection. Journal of Consulting and Clinical Psychology, 5,783-792.

[7] Colarossi, L.G., and Jacquelynne S. Eccles. 2003. "Differential effects of support providers on adolescents' mental health." Social Work Research, 27(1), 19-30.

[8] Collins, W. A. (2003). More than myth: The developmental significance of romantic relations during adolescence. Journal of Research on Adolescence, 13, 1-24.

[9] Connolly, J. A., Craig, W., Goldberg, A., \& Pepler, D. (1999). Conceptions of cross-sex friendships and romantic relations in early adolescence. Journal of Youth and Adolescence, 28, 481-494.

[10] Devi,S. and Mayuri,K. (2003). The effects of family and School on the Academic Achievement of Residential School Children. Journal of Community Guidance and Research 20(2): 139-149.

[11] DuRant, R. H., Getts, A., Cadenhead, C, Emans, S. J., \& Wood, E. R. (1995). Exposure to violence and victimization and depression, hopelessness, and purpose in life among adolescents living in and around public housing. Developmental and Behavioral Pediatrics, 16, 233-237.

[12] Garbarino, J. (1992). Children and families in the social environment (2nd ed.). New York: Walter de Gmyter.

[13] Garbarino, J. (1995). Raising children in a socially toxic environment. San Francisco, CA: Jossey-Bass.

[14] Hepler, J. B. (1994). Evaluating the effectiveness of a social skills program for preadolescents. Research on Social Work Practice. 4, 411-435.

[15] James R. Ciesla and Ping Yao(2011), Validation of a Targeted Peer Relations Scale for Adolescents Treated for Substance Use Disorder: An Application of Rasch Modeling, Substance Abuse Vol.5, pp-35-44. 
[16] Joyce.L.Epstein \& Jame M.Mcpartland (1976). The Concept of Measurement of Quality of School life, American Educational Research Journal, Vol.13, No.1 pp.15-30.

[17] KamlajeetKaur Mehta (1994), "Parent child relation-An imp. envtal variable influencing intelligence of children, Journal of Psychological Researches Vol-38 PP 10-13.)

[18] Kundu, Ramanath; Basu, Jayanti (1991). Frustration reactions as predictors of academic achievement and personality dimensions of school children. Psychological Studies, Vol 36(3), 146-155.

[19] Kupersmidt, J. B., \& Patterson, C. J. (1991). Child-hood peer rejection, aggression, withdrawal, and perceived competence as predictors of self-reported behavior problems in preadoles-cence. Journal of Abnormal Child Psychol-ogy, 19, 427-449.

[20] La Greca, A. M., \& Prinstein, M. J. (1999). The peer group. InW. K. Silverman \& T. H. Ollendick (Eds.), Developmental issues in the clinical treatment of children and adolescents (pp. 171-198.) Needham Heights, MA: Allyn \& Bacon.

[21] Little, S.A., \& Garber, J. (1995). Aggression, depression, and stressful life events predicting peer rejection in children. Development and Psychopathology, 7, 845-856.

[22] PrahbhjotMalhi (2000), Guiding Parents in effective disciplining strategies that work, journal of community guidance and research, vol 17, pp 129-141.

[23] Rao N 1989. Parent Child Relation Scale. Agra:National Psychological Corporation.

[24] S. Rueger, C. Malecki, M. Demaray 2010. Relation between multiple sources of perceived social support and psychological and academic adjustment in early adolescence: Comparisons across gender. Journal of Youth and Adolescence, 39 (2010), pp. 47-61.

[25] Scholte RHJ, van Lieshout CFM, van Aken MAG. Perceived relational support in adolescence: dimensions, configurations, and adolescent adjustment. J Res Adolesc. 2001;11:71-94.

[26] Shanty, K.J \&Anita Ravindran (1998) Parental Discplinary practices and adolescent reactions to frustration, Journal of community guidance \& Research, vol 15 pp 55-61.

[27] Sowaid.M et al (1986), A study of Parent child interaction and achievement motivation among tribal high school students, Journal of Institute of Educational Research 10(3), pp. 24-27

[28] Steinberg L; Lamborn, S.D; Dornbusch, S.M \& Darling N (1992) Impact of parenting practices on adolescent achievement Authoritative parenting school involvement and encouragement to succeed. Child Development, 63, 1266-1281.

[29] SudhaKatyal\&PromilaVasudeva (1998) affect of socio-personal Factors on Academic stress among Adolescents, Indian Journal ofApplied Psychology, vol 35 pp 35-37.

[30] Suman L.N (1997) Parent-Child relation and achievement motivation journal of psychological researches, vol 41 pp 66-73.

[31] Suman L.N and A.Umapathy (2003), Parent Child Relation And Achievement Motivation, Indian Psychological review, 61, 20-27.

[32] Sunitha, B., and Mayuri,K., (2001). Age and Gender differences on factors affecting high academic achievement. Journal of Community guidance and Research 18(2): $197-208$.

[33] Uma Devi L \& Royal U.J.R (2004) Adolescents perception About Family Environment and Emotional Intelligence, Indian psychological Review, vol 62, pp 157-167.

[34] Vernberg, E. M. (1990). Psychological adjustment and experiences with peers during early adolescence: Reciprocal, incidental, or unidirectional relations? Journal of Abnormal Child Psychology,18, 187-198.

[35] Wentzel, K. R. \& Asher, S. R. (1995). The academic lives of neglected, rejected, popular, and controversial children. Child Development. 66, 754-763.

[36] World Health Report 2001 - Mental Health: New Understanding, New Hope, World Health Organization, 2001. 